\title{
基于系统生物学和病证结合模型对中医证候 表征的研究
}

刘进娜 ${ }^{(1)}$, 谢鸣 ${ }^{(1 *}$ ，赵静 ${ }^{(1)}$, 杨宏晔 ${ }^{(2)}$, 沈俊辉 ${ }^{(3)}$, 王帮众 ${ }^{(1)}$, 刘碧原 ${ }^{(1)}$, 张媛风 ${ }^{(1)}$

(1) 北京中医药大学基础医学院, 北京 100029 ;

(2) 中国医学科学院基础医学研究所, 北京 100005 ;

(3) 北京中医药大学信息中心, 北京 100029

* 联系人, E-mail: xieming603@263.net

收稿日期: 2016-04-13; 接受日期: 2016-06-13

国家自然科学基金(批准号: 81373541)资助

摘要证候, 作为中医临床诊治的重要依据, 是中医辨证论治经验中的核心要素和学理支点, 认识中医证候的 现代内涵对于揭示中医辨证论治经验的科学内涵具有重要意义，也是当前中医药研究中的一个难点. 本研究基 于中医证候的特点和 2 型糖尿病的现代病理学认识, 运用系统生物学原理, 在建立 2 型糖尿病病证演变大鼠 (Rattus norvegicus) 模型的基础上, 动态观测模型动物因时演变中跨系统多维指标群的变化, 比较中医辨治经验 的相关方药对模型演变不同阶段的千预效应, 引入有关数理分析方法对多批实验数据进行系统分析, 以探讨 $\mathrm{T} 2 \mathrm{DM}$ 疾病发展中的中医证候演变特点及其现代表征。结果发现，由高糖高脂喂饲联合 STZ 注射复制出的 $\mathrm{T} 2 \mathrm{DM}$ 大鼠模型在其发展的不同阶段表现出中医证候(气阴二虚、痰浊、瘀血)演变的特点和跨系统多指标群的组 合特征, 涉及现代医学糖脂代谢、神经一内分泌、氧化应激、炎症反应、血管活性等病理机制; 相关方剂对于不 同阶段的模型均有不同程度的千预作用，其中因证治方则表现出一定的效应优势，且与相应阶段的病证指标群 具有一定的关联. 该项目从证候演变的角度为论证中医辨证论治中“方证相关”经验的合理性提供了一定的科学 依据, 对于建立具有中医辨证论治特色的病证结合的实验治疗学平台具有重要意义.

关键词病证结合模型, 2 型糖尿病，中医证候，方药千预，方证相关

辨证论治是中医诊疗学的特色之一, 高度体现 了中医个体化的诊疗学思想. 辨证论治落实于临床 则表现为“辨证-立法-组方-用药”的高度统一，其中 辨证，即基于中医四诊信息对当前患者所现证候的
病机(病理)做出判断，并成为之后确立治法和选方遣 药的重要依据.

中医证候临床通常以一组相关症状和体征的集 合为表征，证候蕴含的病机(病邪、病性、病位、病势

引用格式: 刘进娜, 谢鸣, 赵静, 等. 基于系统生物学和病证结合模型对中医证候表征的研究. 中国科学: 生命科学, 2016, 46: 913-928 Liu J N, Xie M, Zhao J, et al. Characterization of TCM syndrome using model of disease combined with syndrome based on principle of system biology. Sci Sin Vitae, 2016, 46: 913-928, doi: 10.1360/N052016-00026 
等)则是中医关于疾病发生演变中某一阶段病理本质 的认识. 证候具有整体、动态的特性, 表现为具有跨 系统和随时相演变的特征; 同时证候又具有模糊和 不确定性, 表现为临床辨证中的信息粗放和诊断标 准不统一.中医证候与现代医学疾病各自具有不同 的概念内涵，但二者之间又具有某种交集，如所谓的 “同病异证”(同一疾病因不同个体或不同阶段表现出 不同的证候)和“异病同证”(不同疾病因不同的患者或 疾病不同阶段表现出相同的证候).

证候，作为中医临床诊疗的基本单元和立法组 方及治疗效应评价的重要依据, 是中医辨证论治经 验中核心要素和学理支点, 认识中医证候的现代内 涵对于揭示中医辨证论治经验的科学内涵具有举足 轻重的意义, 而探索中医证候的现代内涵也一直是 中医现代研究的热点领域. 由于建立在整体、动态观 基础上的中医证候具有跨系统和随时相演变的特征, 临床的经验性又使中医证候具有一定模糊和不确定 性. 因此, 有关中医证候的现代研究常常面临来自于 认识论或方法论方面的质疑 ${ }^{[1,2]}$, 如有学者认为, 临 床研究中, 医生通过四诊(望、闻、问、切)获取患者 信息及据此作出证候的判断, 具有较强的主观和经 验性, 加上目前有关证候判断标准的不统一, 致使临 床对于证候的认定缺乏其客观性和公认性 ${ }^{[3]}$, 而以西 医异常指标的上下限 ( $95 \%$ 正常人群的均数分布) 作为 判断标准及仅以个别或少数指标来探查证候的实质 显然具有明显的局限性 ${ }^{[4]}$; 实验研究中, 模型动物对 于人临床证候的表征有限, 且源自不同方法复制出 的同一证候模型具有一定的异质性, 与证候关联的 实验室指标变化具有不确定性. 反映了证候现代内 涵的表征仍是当前中医证候研究中的一个难点. 新 近通过实验室相关指标的比较以认识同病异证的内 涵差异 ${ }^{[1,5]}$, 利用数据挖掘技术分析中医证候构成 ${ }^{[6,7]}$, 从生物网络角度探讨中医寒热证候的生物学基础 ${ }^{[8,9]}$, 从病证结合及系统生物学角度探讨证候的现代内 涵 ${ }^{[10,11]}$ 等研究, 对于中医证候的认识具有一定的方 法学启示意义. 总体上看, 有关研究尚缺乏必要的系 统性和评价性. 为此本文提出中医证候内涵研究的 基本思路(图 1).

2 型糖尿病(T2DM) 是一种严重影响人类健康的 内分泌代谢性疾病, 主要由胰岛素作用受损(胰岛素 抵抗)和胰岛素分泌障碍两方面缺陷导致. 但其发病

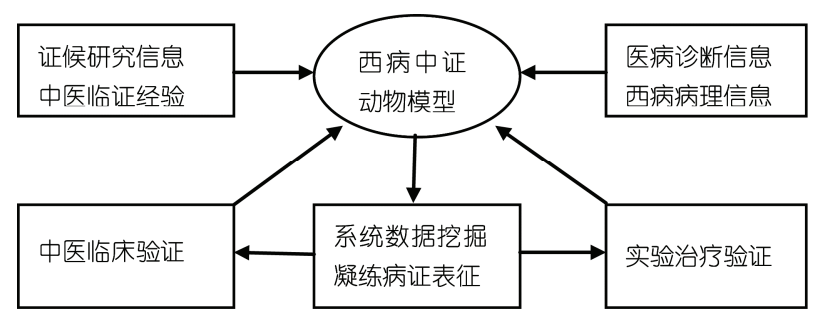

图 1 基于病证结合的中医证候现代内涵研究的基本思路

机制复杂, 现代医学有关糖尿病发病机制目前有多 种不同认识，涉及糖代谢、糖脂毒性、神经-内分泌调 节异常、氧化应激、炎症损伤等多种学说 ${ }^{[4,12,13]}$. 有 关 T2DM 病程及其病理发展的研究虽然有过一些报 道 ${ }^{[14 ~ 16]}$, 但由于 2 型糖尿病具有异质性和隐匿性, 其 病程长且持续发展, 临床经诊断的患者不可避免地 会接受包括药物在内的各种疗法的干预, 加上临床 研究的限制, 至今为止人们对该病的发病及其病理 演变规律仍不清楚.

糖尿病属于中医“消渴”的范畴, 中医认为本病 多因先天禀赋不足、饮食不节、过食肥甘、劳逸失度、 外感六淫、内伤七情等多种因素, 损伤肺、胃、肾等 多个脏腑, 导致阴虚燥热而发病. 目前认为 T2DM 的 病机主要涉及阴虚、热盛、痰湿、疙血等 ${ }^{[17]}$, 临床辨 证分型主要有气阴两虚、痰湿内蕴、阴虚热盛、阴阳 两虚、瘀血阻络, 病位多涉及肝肾、脾胃或肺 ${ }^{[18]}$, 其 中以气阴两虚、痰湿内蕴、阴虚热盛和瘀血阻络证为 多见, 尤以气阴两虚最为多见 ${ }^{[19,20]}$. 临床曾观察到, $\mathrm{T} 2 \mathrm{DM}$ 发展中可见到中医证候演变的某种规律 ${ }^{[21]}$, 如不同病程的 T2DM 患者中 $80 \%$ 以上有气阴两虚的 表现, 且常兼多种证型 ${ }^{[22]}$, 随着病程发展, T2DM 患 者会较多出现疾湿、瘀血证, 气阴两虚证多出现于病 程的始终 ${ }^{[23,24]}$.

之前的一些研究发现, 中医阴虚和阳虚证患者 血浆 cAMP, cGMP 含量及其比值出现相反的变化趋 势 ${ }^{[25]}$, 痰浊证患者多伴有血脂 (血清胆固醇、 $\mathrm{TG}$, LDL-C) 的异常升高 ${ }^{[26,27]}$, 血瘀证患者则常伴有血液 流变学指标的异常 ${ }^{[28]}$. 有关 T2DM 中医证型与现代 医学实验室指标关系的探查发现, T2DM 气阴两虚型 患者血浆 cAMP 和血清胰岛素水平明显高于正常对 照组 ${ }^{[29]}$, 其痰浊型患者多伴有血脂异常 ${ }^{[30]}$, 大多数 患者出现血瘀证并且伴有血液流变学的异常 ${ }^{[31]}$. 另 有研究显示, 腺苷酸代谢 ${ }^{[32]}$ 、脂肪代谢、血液流变学 等方面的病理生理变化与中医证候分型之间存在关 


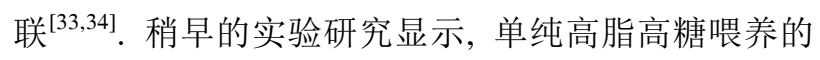
$\mathrm{SD}$ 大鼠(Rattus norvegicus) 在 IR 形成过程中可见中医 气虚-气阴两虚-气阴两虚兼痰浊-气阴两虚兼痰浊血 疼的证候变化 ${ }^{[35]}$. 之后的研究发现, 采用高脂高糖持 续喂饲大鼠, 5 周后一次性腹腔注射小剂量链腿菌素 (streptozocin, STZ)诱导出 T2DM 模型大鼠在成模后 7 12 周呈现出以 2 型糖尿病 IR 为病理背景, 出现以 中医气阴两虚为基本病机及气阴两虚证、气阴两虚兼 痰浊证、气阴两虚兼痰瘀证的先后演变趋势 ${ }^{[36]}$, 被认 为是一个以 $\mathrm{T} 2 \mathrm{DM}$ 为基本病理且因时呈现中医不同 证候的西病中证的病证结合模型.

基于上述现代医学有关 2 型糖尿病的病理认识 和中医临床辨治经验的背景, 本文根据中医证候的 特征和现代系统生物学原理, 在建立中西医结合 2 型 糖尿病病证演变大鼠模型的基础上, 试图通过对模 型动物因时演变中跨系统多维指标群的系统观测, 同时引入有关数理分析方法对多批实验数据进行系 统分析, 以探讨基于疾病不同时相的中医证候演变 特点及其现代内涵表征.

\section{1 材料与方法}

\section{1 材料}

(1) 动物. 健康雄性 SD 大鼠 300 只, 体重 $(190 \pm 10) \mathrm{g}$, 级别 $\mathrm{SPF}$, 动物许可证号为 $\mathrm{SCXK}$ (京)2011-0004, 由斯贝福(北京)实验动物科技有限公 司提供. 所有动物提前 1 周购入, 6 只/笼. 光照节律 12L: 12D(6: 00 18: 00), 室温 $20^{\circ} \mathrm{C} \sim 25^{\circ} \mathrm{C}$, 湿度： $40 \% \sim 70 \%$, 保持安静.

(2) 饲料. 普通饲料: 由北京科澳协力饲料有 限公司加工提供. 许可证号：SCXK(京)2009-0012, 生产批号: 13103212. 高脂高糖饲料: 由北京科澳协 力饲料有限公司加工提供. 等级: A 级, 许可证号: $\mathrm{SCXK}$ (京)2014-0010. 饲料配方： $2 \%$ 胆固醇、0.5\%牛 胆酸钠、 $10 \%$ 猪油、5\%蔗糖、5\%蛋黄粉, $77.5 \%$ 基础 饲料.

(3) 药物. 中医干预方药: 基于文献调查获得 的中医治疗糖尿病的常用药谱, 根据 2 型糖尿病的基 本病机(气阴两虚、痰浊、血瘀)和治法, 参考药物使 用频率, 笁选出体现益气养阴、化痰、活血的药味, 按 组方配伍原则, 分别设计出针对气阴两虚证、气阴二 虚兼痰浊证、气阴二虚兼痰浊瘀血证的三首治方：
( i ) 益气养阴方(A 方)由干地黄、多黄芪、山药、麦 冬、山英肉组成; (ii) 益气养阴化痰方(B 方)由干地 黄、多黄芪、山药、麦冬、山英肉、获苓、泽泻、陈 皮所组成; (iii) 益气养阴化痰活血方(C 方)由干地 黄、多黄芪、山药、麦冬、山英肉、获苓、泽河、陈 皮、丹皮、丹参、赤药所组成. 处方剂量为临床成人 每日用量. 以上中药材均购自北京同仁堂药材有限 责任公司，经鉴定符合药用标准. A, B, C 各方按汤药 水提法提取, 低温干燥、制粒, 分别制成每克含生药 $1.578,2.016,2.138 \mathrm{~g}$ 的颗粒, 备用. 灌胃前分别用蒸 馏水配制成适宜浓度的药液.


$\times 1$ 板/盒, 生产: 日本武田药品工业株式会社, 分装: 天津武田药品有限公司, 生产批号: 130406, 产品批 号: 165A), 研成细粉, 用蒸馏水配制成浓度为 0.15 $\mathrm{mg} / \mathrm{mL}$ 的溶液. $4^{\circ} \mathrm{C}$ 保存, 保质期 3 天. 灌胃前将药液 复温至常温后使用.

(4) 试剂. 链脲佐菌素(streptozocin, Lot: WXBB2432V), 西格玛奥德里奇贸易有限公司; 柠檬 酸和柠檬酸三钠(Lot: 1307202 \& 1303262), 西陇化工 股份有限公司. 肾素(Renin ELISA Kit, 20140318)、抵 抗素(Resistin ELISA Kit, 20140318)、肌肉素(Musclin ELISA Kit, 20140312)、胰淀素(Amylin ELISA Kit, 20140310)、核因子(NF-kB ELISA Kit, 20140312)、皮 质醇(CORT ELISA Kit, 20140318)、肾上腺皮质激素 (ACTH ELISA Kit, 20140316), 均由安迪生物科技(上 海)有限公司提供. 大鼠胰岛素酶联免疫试剂盒(Rat INS ELISA Kit, 20150420.60207R)、大鼠胰高血糖素 酶联免疫试剂盒(Rat GC ELISA Kit, 20150420. 60175R)、大鼠胰岛素降解酶联免疫试剂盒(Rat IDE ELISA Kit, 20150420.60353R)、大鼠生长抑素酶联免 疫试剂盒(Rat SS ELISA Kit, 20150420.60350R)、大鼠 环磷酸腺苷酶联免疫试剂盒(Rat cAMP ELISA Kit, 20150420.60320R)、大鼠环磷酸鸟苷酶联免疫试剂盒 (Rat cGMP ELISA Kit, 20150420. 60161R)、大鼠 C 反 应蛋白酶联免疫试剂盒(Rat CRP ELISA Kit, 20150420. 60199R)、超微量 $\mathrm{Na}^{+}-\mathrm{K}^{+}$-ATP 酶测定试剂 盒 $\left(\mathrm{Na}^{+}-\mathrm{K}^{+}\right.$-ATPase assay kit, 20150115.40041)、一氧化 氮合成酶分型测试盒(nitric oxide synthase assay kit, 20150115.40016)、总超氧化物歧化酶(total superoxide dismutase, T-SOD)测试盒(total superoxide dismutase assay kit, 20141118.40001)、大鼠瘦素酶联免疫试剂盒 
(Rat LEP ELISA Kit, 20150420.60208R)、甘油三酯测 试盒(triglyceride assay kit, 20151015.30028)、总胆固 醇测试盒(total cholesterol assay kit, 20151015.30027)、 低密度脂蛋白测试盒(low density lipoprotein assay kit RGB \& CHN Lot: 20151015.30030)、高密度脂蛋白测 试盒(high density lipoprotein assay kit RGB\& CHN Lot: 20151015.30029)、游离脂肪酸测试盒 (nonesterified free fatty acids assay kit RGB \& CHN Lot: 20141118.40030)、大鼠载脂蛋白 A 酶联免疫试 剂盒(rat Apo-A ELISA kit, 20150420.60336R)、大鼠视 黄醇结合蛋白 4 酶联免疫试剂盒(rat RBP4 ELISA kit, 2015 0420.60086R)、大鼠血栓素 B2 酶联免疫试剂盒 (rat TXB2 ELISA Kit, 20150420.60269R)、大鼠 6-酮前 列腺素 $F 1 \alpha$ 酶联免疫试剂盒 (Rat 6-Keto-PGF1 $\alpha$ ELISA Kit, 20150420.60281R)、大鼠同型半胱氨酸酶 联免疫试剂盒(rat Hcy ELISA kit, 20150420.60210R), 均由瑞格博生物科技公司(北京)提供.

(5) 主要仪器. 血压仪: BP-98A 型, 日本株式 会社; 采血针: 注式 soft 2 型, Lot: 01-121276, 苏州施 莱医疗器械有限公司; 血糖试纸: Ultra 稳豪, Lot: 3569812, 强生(中国)医疗器材有限公司 (上海); 血糖 仪: Ultra Easy 型, Lot: R1288052X, 强生(中国)医疗 器材有限公司; 糖化血红蛋白仪: 挪威小旋风型, AXIS-SHIELD 公司; 电子天平: PL6001-S 型, 梅特勒托利多仪器有限公司(上海); 抓力仪: YLS-13A 型, Lot: 008070020, 济南益延科技发展有限公司; 离心 机: Sigma 3K30 型, Sigma 公司(美国); 生化仪: UniCelDxC 600 Synchron 型, Beckman Coulter(美国) 公司; 酶标仪: Thermo Multiskan MK3 型, Thermo Scientific(芬兰雷勃)公司.

\section{2 实验方法}

（1）模型建立及其动态多点观察. 以高脂高糖 饲料喂养 $5 \mathrm{w}+$ 腹腔注射小剂量 STZ 的方法建立 2 型 糖尿病大鼠模型, 注射 STZ 后第 3 天, 尾静脉采血检 测大鼠空腹血糖, 选择空腹血糖 $\geqslant 11.1 \mathrm{mmol} / \mathrm{L}$ 的大 鼠纳入模型组 $(\mathrm{M})$, 之后继续喂养高脂饲料; 同设正常 组 $(\mathrm{N})$, 给予正常饲料喂养. 连续动态观测正常组和模 型组大鼠实验第 7 8 周、第 9 10 周和第 11 12 周 3 个时间段的相关指标, 每个阶段每组各 10 只大鼠.

（2）模型的中医方药动态干预. 上述模型复制 成功后, 分别于实验第 7 周、第 9 周、第 11 周的第 1
天,由模型动物中随机分为模型组、中药 $\mathrm{A}$ 方组、中 药 B 方组、中药 C 方组和西药组, 每组各 12 只; 其 中中药3 组分别给于 $\mathrm{A}$ 方 $\left(3.37 \mathrm{~g} \mathrm{~kg}^{-1}\right.$ 天 $\left.^{-1}\right) 、 \mathrm{~B}$ 方 (3.84 $\mathrm{g} \mathrm{kg}^{-1}$ 天 $\left.^{-1}\right) 、 \mathrm{C}$ 方 $\left(4.80 \mathrm{~g} \mathrm{~kg}^{-1}\right.$ 天 $^{-1}$ )灌胃(给药量按药 理学成人与大鼠用量折算比例换算而成), 西药治疗 组给予盐酸吡格列酮 $\left(1.35 \mathrm{mg} \mathrm{kg}^{-1}\right.$ 天 $^{-1}$ ) 灌胃, 连续 灌胃 2 周; 正常组(由同批试验中的正常组中随机抽 取)和模型组分别灌服等量蒸馏水. 期间模型组和给 药各组大鼠均继续给予高脂饲料喂养. 于第 $8,10,12$ 周末各组大鼠禁食 $8 \mathrm{~h}$ 后腹腔麻醉, 取材(血和相关脏 器) 并检测相关指标.

（3）指标测定. 包括中医外观表征、T2DM 基本 指标、IR 指标; 氧化应激、糖脂代谢、血管调节、神 经-内分泌等多组共 49 个指标.

外观指标: 大鼠的毛发色泽(fur lustre)、行为状 态(activity)、舌与尾颜色(color of tongue tail)、体重 (weight)、抓握力 (grip)、血压(bp)、饮食(food)、饮水 (water)、大便(defecation)及小便量(urine)等, 采用常 规方法观测.

实验室指标：（i ）T2DM 基础指标：包括空腹血 糖(FPG)、血清胰岛素(Fins)、糖化血红蛋白(HbA1c), 计算胰岛素敏感指数(ISI, ISI=1/FPG $\times$ Fins); 非正态 分布取自然对数为 IAI, IAI=InISI)和胰岛素抵抗指数 (IRI, IRI =FPG $\times$ Fins/22.5); (ii) IR 相关指标: 肌肉、 肝脏、脂肪组织的胰岛素受体(InsR)、肌肉和脂肪葡 萄糖转运蛋白-4(GLUT4) 及肝脏葡萄糖转运蛋白2(GLUT2); (iii) 肤岛素调节因子: 血清胰岛素降解 酶(IDE)、血清胰高血糖素(GC)、血清生长抑素(SS); (iv) 脂代谢: 血清总胆固醇(TC)、甘油三脂(TG)、高 密度脂蛋白(HDL-C)、低密度脂蛋白(LDL-C); 血浆游 离脂肪酸(FFA)、载脂蛋白(Apo-A); ( $\mathrm{v}$ ) 炎症因子: 血清瘦素 (Leptin)、C 反应蛋白 (CRP)、核因子$\kappa B(N F-\kappa B)$; (vi) 凝血及血管调节因子：血浆纤维蛋 白原(FIB)、血浆血栓素(TXB2)、血浆 6-酮-前列环素 F1 $\alpha(6-k e t o-P G F 1 \alpha)$ 、肾素(renin); (vii) 相关酶: 红细 胞膜钠-钾-ATP 酶 $\left(\mathrm{Na}^{+}-\mathrm{K}^{+}-\mathrm{ATP}\right)$ 、血浆超氧化物歧化 酶(SOD)、血清组织型一氧化氮合酶(iNOS); (viii) 其 他: 血清皮质醇(CORT)、促肾上腺皮质激素( $\mathrm{ACTH})$ 、 血浆环磷酸腺苷/环磷酸鸟苷 (cAMP/cGMP)、血清视 黄醇结合蛋白(RPB4)、同型半胱氨酸(Hcy)、抵抗素 (resistin)、肌肉素(musclin)、胰淀素(amylin). 采用酶 联免疫或生化方法检测. 


\section{3 数据处理及分析}

数据由常规统计学处理 (采用 SPSS17.0 for windows 统计软件, 各组数据均以 $\bar{x} \pm \mathrm{SE}$ 表示), 结果 采用直观分析; 系统原始数据分别采用层次聚类、决 策树及信息熵分析.

直观方法: 基于正常组与模型组、模型组组内不 同阶段二个不同维度, 分别整理出其中经统计学处 理后各点正常与模型组间差异具有显著性意义 $(P<$ 0.05)的指标谱(相对于正常组的阳性指标)和模型组 内各点差异具有显著性意义的指标谱(相对于前一点 具有差异的变化指标); 在此基础上, 围绕模型大鼠 成模全程的共性指标和各阶段的相对特征性指标进 行比较分析.

层次聚类分析: 将多批次实验的原始数据作为 一个整体, 基于层次聚类算法的主要思想, 采用无监 督的层次聚类算法对这些指标向量进行分析, 以总 体指标间的距离来衡量样本之间的相似度, 并在此 基础上利用 $\mathrm{R}$ 语言包 gplots 中的层次聚类函数绘制热 图, 以直观显示出正常对照组和模型组在这些指标 上的差异特点.

信息熵/信息增益分析：信息熵是表示系统混乱 程度的统计量, 信息增益表示系统由于分类所获得 的信息量, 通常使用信息摘的减少值进行定量描述. 信息熵越小, 信息增益越大, 则表明该指标区分对应 研究对象不同类别的能力越强(一般信息增益值大于 0.5 的指标需要关注). 本次将多批次实验的原始数据 作为一个整体, 通过信息增益分析, 以探讨实验各阶 段中正常组与模型组、模型组相邻阶段的区分度较高 的指标或指标群.

\section{2 结果}

\section{1 基于常规统计学分析获得的模型各阶段指标} 变化

由表 1 和 2 可见, 模型组成模后各阶段前后比较: (i ) 与 5 周 +3 天相比, 成模后第一阶段的差异指标 有： BP, Weight, Water, Urine, IAI, IRI, SOD, Liver-InsR, Defecation, cAMP/cGMP, iNOS, FPG, Fins, Renin, Food; (ii) 与成模后第一阶段相比, 第 二阶段的差异指标有: Weight, BP, Grip, Water, Urine, IAI, IRI, TG, TC, HDL-C, LDL, C, Apo-A, FIB, SOD, Liver-InsR; (iii) 与成模后第二阶段相比, 第三阶段
的差异指标有: BP, Grip, TXB2, LDL-C, Fat-GLUT4, Muscle-Ins R, Muscle-GLUT4, Amylin.

以与正常组比较具有显著性差异为背景, 比较归 纳出实验全程中(由第 5 周 +3 天 第 12 周)模型组内 3 个阶段的前后差异具有显著性和无显著性意义的指标 (表 3).

由表 3 可见, 在各阶段有显著性差异的指标谱 中, 成模后第一阶段较之 5 周 +3 天的差异指标: BP, Food, Water, Defecation, Urine, FPG, IAI, IRI, iNOS, SOD, Liver-InsR; 成模后第二阶段较之第一阶段的 差异指标: BP, Water, Urine, Grip, Weight, IAI, IRI, TG, TC, HDL-C, LDL-C, Apo-A, SOD, FIB, Liver-InsR; 成模后第三阶段较第二阶段的差异指标: BP, Grip, LDL-C, Fat-GLUT4, TXB2, Amylin, Muscle-InsR, Muscle-GLUT4.

通过比较表 1 3, (i ) 在各阶段前后比较无显著 性差异的指标谱中: 贯穿 4 个时间点(即实验 5 周 +3 周 12 周, 成模及成模之后的 3 个阶段)的指标: BP, Food, Water, Defecation, Urine, FPG, IAI, IRI, FFA, Leptin, iNOS, $\mathrm{Na}^{+}-\mathrm{K}^{+}$-ATPase, SOD, CRP, IDE, Liver-GLUT2, Liver-InsR; 贯穿 3 个时间点(即实验第 6 12 周, 成模后第 1 3 阶段)的指标: BP, Food, Water, Defecation, Urine, FPG, IAI, IRI, FFA, Leptin, iNOS, $\mathrm{Na}^{+}-\mathrm{K}^{+}$-ATPase, SOD, CRP, IDE, Liver-GLUT2, Liver-InsR, Fins, GC, cAMP/cGMP, NF-кB, HbAlc, CORT, Resistin, Musclin, ACTH, SS; 贯穿 2 个时间点 (即实验 8 12 周, 第 2 3 阶段)的指标: BP, Food, Water, Defecation, Urine, FPG, IAI, IRI, FFA, Leptin, iNOS, $\mathrm{Na}^{+}-\mathrm{K}^{+}$-ATP, SOD, CRP, IDE, Liver-GLUT2, Liver-InsR, Fins, GC, cAMP/cGMP, NF-kB, HbA1c, CORT, Resistin, Musclin, ACTH, SS, Fat-InsR, weight, Grip, TG, TC, HDL-C, LDL-C, Apo-A, FIB, Hcy, RPB4, Fat-GLUT4; 最后 1 个时间点(即实验 10 12 周, 第 3 阶段)的指标: TXB2, 6-keto-PGF1a, Renin, Muscle-InsR, Muscle-GLUT4, Amylin; (ii) 各阶段所 特有的指标: 成模后第一阶段：BP, Food, Water, Defecation, Urine, FPG, IAI, IRI, FFA, Leptin, iNOS, $\mathrm{Na}^{+}-\mathrm{K}^{+}$- ATPase, SOD, CRP, IDE, LiverGLUT2, Liver-InsR, Fins, GC, cAMP/cGMP, NF-кB, HbA1c, CORT, Resistin, Musclin, ACTH, SS; 成模后 第二阶段: Fat-InsR, Weight, Grip, TG, TC, HDL, LDL, Apo-A, FIB, Hcy, RPB4, Fat-GLUT4; 成模后第 三阶段：TXB2，6-keto-PGF1 $\alpha$, Muscle-IR, MuscleGLUT4, Renin, Amylin. 
2.2 基于数据挖掘获得的模型及其各阶段的特征 性指标

正常组与模型组指标和模型组内各不同阶段指 标的层次聚类分析的结果见图 2 和 3. 图中的每行为 一个指标所有样本中的取值, 每列是一个样本在所
有指标中的取值，最右边的编号是指标的序号; 最下 边的编号是样本的编号. 图上边和左边的层次聚类 树, 分别是根据每个样本在所有指标上和针对每个 特征在所有样本中的取值模式. 通常在聚类树上越 近的样本，取值模式越相似，即按从近到远的层层划

表 1 基于正常组模型大鼠各阶段的差异指标谱

\begin{tabular}{|c|c|c|c|}
\hline 成模前(5 周+3 天) & 成模后第一阶段 & 成模后第二阶段 & 成模后第三阶段 \\
\hline $\mathrm{BP}$ & BP & BP & $\mathrm{BP}$ \\
\hline Food & Food & Food & Food \\
\hline Water & Water & Water & Water \\
\hline Defecation & Defecation & Defecation & Defecation \\
\hline Urine & Urine & Urine & Urine \\
\hline FPG & FPG & FPG & FPG \\
\hline IAI & IAI & IAI & IAI \\
\hline IRI & IRI & IRI & IRI \\
\hline FFA & FFA & FFA & FFA \\
\hline Leptin & Leptin & Leptin & Leptin \\
\hline iNOS & iNOS & iNOS & iNOS \\
\hline $\mathrm{Na}^{+}-\mathrm{K}^{+}$-ATPase & $\mathrm{Na}^{+}-\mathrm{K}^{+}$-ATPase & $\mathrm{Na}^{+}-\mathrm{K}^{+}$-ATPase & $\mathrm{Na}^{+}-\mathrm{K}^{+}$-ATPase \\
\hline SOD & SOD & SOD & SOD \\
\hline CRP & CRP & CRP & CRP \\
\hline IDE & IDE & IDE & IDE \\
\hline Liver-GLUT2 & Liver-GLUT2 & Liver-GLUT2 & Liver-GLUT2 \\
\hline Liver-InsR & Liver-InsR & Liver-InsR & Liver-InsR \\
\hline Fat-InsR & Fat-InsR & Fat-InsR & Fat-InsR \\
\hline \multirow[t]{27}{*}{$\mathrm{TC}$} & GC & GC & GC \\
\hline & cAMP/cGMP & cAMP/cGMP & cAMP/cGMP \\
\hline & $N F-\kappa B$ & $N F-\kappa B$ & $N F-\kappa B$ \\
\hline & $\mathrm{HbA1c}$ & $\mathrm{HbA1c}$ & $\mathrm{HbA} 1 \mathrm{c}$ \\
\hline & CORT & CORT & CORT \\
\hline & Resistin & Resistin & Resistin \\
\hline & Musclin & Musclin & Musclin \\
\hline & ACTH & ACTH & АCTH \\
\hline & Fins & Fins & Fins \\
\hline & SS & SS & SS \\
\hline & & Weight & Weight \\
\hline & & Grip & Grip \\
\hline & & $\mathrm{TC}$ & $\mathrm{TC}$ \\
\hline & & TG & TG \\
\hline & & HDL-c & HDL-c \\
\hline & & LDL-c & LDL-c \\
\hline & & Apo-A & Apo-A \\
\hline & & FIB & FIB \\
\hline & & Hcy & Hcy \\
\hline & & RPB4 & RPB4 \\
\hline & & Fat-GLUT4 & Fat-GLUT4 \\
\hline & & & TXB2 \\
\hline & & & 6-keto-PGF1 $\alpha$ \\
\hline & & & Muscle-InsR \\
\hline & & & Muscle-GLUT4 \\
\hline & & & Renin \\
\hline & & & Amylin \\
\hline
\end{tabular}


分, 即离得越近的指标(特征), 它们在所有指标和所 有样本中的取值模式越相似. 属性序号 1 49 按顺序 对应的指标是: FPG, Fins, IAI, IRI, Hba1c, IDE, GC, SS, BP, Weight, Gripe, Food, Water, Defecation, Urin, LEP, CRP, cAMP/cGMP, iNOS, $\mathrm{NA}^{+}-\mathrm{K}^{+}-\mathrm{ATP}$, SOD, TC, TG, HDL-C, LDL-C, FFA, Apo-A, RPB4, FIB, 6-Keto-PGF1, TXB2, Hcy, Renin, NF- $\kappa$ B, Resistin, Musclin, Amylin, ACTH, CORT, LiverGLUT-2, Liver-InsR, Muscle-GLUT4, Muscle-InsR, Fat-GLUT4, Fat-InsR, GLP-1, IL-10, Apo-B100, AchE. 由图 2 可以看出, 正常组和模型组 4 个阶段指标 之间均有明显的差异, 分属于较大的两个类, 表明正 常组和模型组两大类指标体系能够进行有效区分.
由图 3 可以看出, 模型组组内 4 个阶段指标之间具有 明显的差异, 分属于较大的四类, 表明模型发展 4 个 时间点(4 个阶段)的四大类指标体系之间能够进行有 效区分，可以进行下一步的比较.

信息增益(熵)分析的结果见图 4 和 5. 图 4 为相 邻观察点的正常组和模型组各指标的信息增益值, 图中每一纵列为按信息增益值大小排列的各对比组 的指标. 信息增益数值大的指标, 适合作为该研究对 象类别的界定指标.一般而言，信息增益值大于 0.6 的指标是需要关注的, 提示研究对象的不同类别对 指标影响很重要. 考虑到各组指标数量及留给一定 的分析空间, 本研究中设定信息增益值大于 0.5 的指

\section{表 2 大鼠成模后各阶段的差异指标谱}

\begin{tabular}{|c|c|c|}
\hline 8 周 (与 5 周 +3 天相比) & 10 周 (与第 8 周相比) & 12 周 (与第 10 周相比) \\
\hline $\mathrm{BP}$ & $\mathrm{BP}$ & $\mathrm{BP}$ \\
\hline Weight & Weight & Grip \\
\hline Water & Water & LDL-C \\
\hline Urine & Urine & Muscle-InsR \\
\hline IAI & IAI & Fat-GLUT4 \\
\hline IRI & IRI & Muscle-GLUT4 \\
\hline SOD & SOD & TXB2 \\
\hline Liver- InsR & Liver- InsR & Amylin \\
\hline Defecation & Grip & \\
\hline cAMP/cGMP & LDL-C & \\
\hline iNOS & Muscle- InsR & \\
\hline FPG & $\mathrm{TC}$ & \\
\hline Fins & HD-CL & \\
\hline Renin & Apo-A & \\
\hline \multirow[t]{2}{*}{ Food } & TG & \\
\hline & FIB & \\
\hline
\end{tabular}

表 3 基于正常组为背景的模型组内各阶段差异指标的比较

\begin{tabular}{|c|c|c|}
\hline 8 周 (与 5 周 +3 天相比) & 10 周(与第 8 周相比) & 12 周 (与第 10 周相比) \\
\hline BP & BP & BP \\
\hline Water & Water & Grip \\
\hline Urine & Urine & LDL-C \\
\hline IAI & IAI & Muscle-InsR \\
\hline IRI & IRI & Fat-GLUT4 \\
\hline SOD & SOD & TXB2 \\
\hline Liver-InsR & Liver-InsR & Amylin \\
\hline FPG & $\mathrm{TC}$ & \\
\hline iNOS & TG & \\
\hline Defecation & LDL-C & \\
\hline \multirow[t]{5}{*}{ Food } & HDL-C & \\
\hline & Apo-A & \\
\hline & FIB & \\
\hline & Grip & \\
\hline & Weight & \\
\hline
\end{tabular}


标作为关注对象, 重点考察增益值等于 1(很好区分 力)和大于 0.5 (较好区分力)的指标. 由图 4 可以看出, (i ) 对于 M1 和 N1, 具有很好区分力的是 IRI, IAI 和 FGP, 较好区分力的是 SOD, CRP, Leptin, Water, Gripe, iNOS, Defecation; (ii) 对于 M2 和 N2, 具有很 好区分力的是 IRI, HbA1c, IAI, BP, FPG, cAMP/cGMP, 较好区分力的是 Resistin, CORT, FFA, iNOS, CRP, SOD, Musclin, Leptin, Fins, NF- $\kappa B$, Gripe, Defecation, $\mathrm{Na}^{+}-\mathrm{K}^{+}$-ATPase, Urine, Food, Water; (iii) 对于 $M 3$ 和 $N 3$, 具有很好区分力的是 IRI, BP, Weight, IAI, CORT, CRP, HbA1c, FPG, $\mathrm{cAMP} / \mathrm{cGMP}$, 较好区分力的是 iNOS, Resistin, Leptin, TG, FIB, FFA, LDL, NF- $\kappa B$, HDL, TC, Gripe, Apo-A, Food, $\mathrm{Na}^{+}-\mathrm{K}^{+}$-ATPase, SOD, Urine, Defecation, Water; (iv) 对于 M4 和 N4, 具有很好区
分力的是 IRI, BP, IAI, HbA1c, Weight, FPG, 较好区 分力的是 Resistin, GC, Fins, TC, CORT, cAMP/cGMP, Fat-GLUT4, TXB2, TG, Fat-InsR, iNOS, SOD, FFA, Liver-GLUT-2, Muscle-InsR, IDE, Muscle-GLUT4, Defecation, Urine, Water, Gripe, Food, $\mathrm{Na}^{+}-\mathrm{K}^{+}-\mathrm{ATP}, \mathrm{FIB}$, Apo-A. 基于上述具有较好 区分力的指标谱进一步进行各阶段动态考察. 由图 4 还可以发现: ( i ) 贯穿于模型发生发展全程 4 个时间 点(第 5 周 +3 天 第 12 周)指标: IRI, IAI, FPG, Gripe, iNOS; (ii) 贯穿于成模后第 1 阶段的指标: IRI, IAI, FPG, Gripe, iNOS, HbA1c, BP, cAMP/cGMP, Resistin, CORT, $\mathrm{Na}^{+}-\mathrm{K}^{+}$-ATPase, SOD, FFA, Food, Water, Urine; (iii) 贯穿于成模后第 2 阶段的指标: IRI, IAI, FPG, Gripe, iNOS, HbA1c, BP, cAMP/cGMP, Resistin, CORT, $\mathrm{Na}^{+}-\mathrm{K}^{+}$-ATPase, SOD, FFA, Food, Water,



图 2 正常组与模型组指标的层次聚类热图

不同的颜色表示数值的高低, 相同的颜色块通常被聚集到一起, 即取值相似的样本或者模式被聚集到一起 


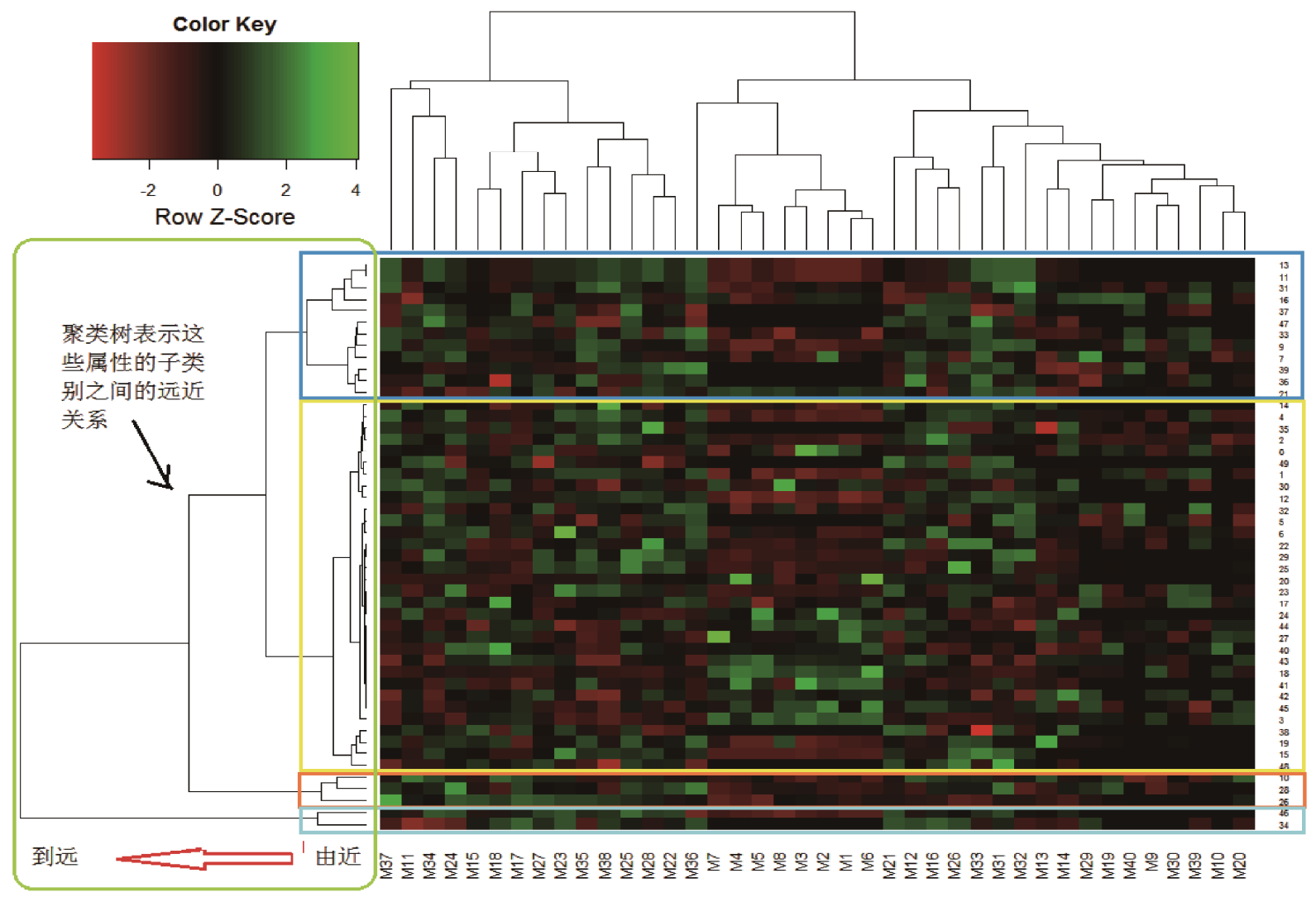

图 3 模型组各阶段指标的层次聚类图

不同的颜色表示数值的高低, 相同颜色块通常被聚集到一起, 即取值相似的样本或模式被聚集到一起

Urine, Weight, TG, TC, FIB, Apo-A; (iv) 仅见于成模 后第 3 阶段的指标有: GC, Fat-GLUT4, TXB2, FatInsR, Liver-GLUT2, Muscle-InsR, IDE, Muscle-GLUT4.

图 5 是模型组内相邻观察点间各指标信息增益 值. 从图 5 中可以看出: (i ) 对于 M1 和 M2, 具有很 好区分力的指标是 $\mathrm{cAMP} / \mathrm{cGMP}$, 具有较好区分力的 指标是 BP, Weight, FPG, IRI, Urine, Food, Gripe, IAI, Water; (ii) 对于 M2 和 M3, 具有很好区分力的指标 是 Weight, 具有较好区分力的指标是 FPG, Apo-A, TG, LDL, FIB, Gripe, Urine, Water; (iii) 对于 M3 和 M4, 具有较好区分力的指标是 BP, Muscle-GLUT4, Muscle-InsR.

2.3 相关方药对于大鼠成模后不同阶段的干预 结果

中药三方对成模后 3 个不同阶段的干预结果见 图 6.

从图 6A 中可以看出, 中药 $\mathrm{A}, \mathrm{B}, \mathrm{C}$ 三方对大鼠成
模后第一阶段的 BP, IRI, $\mathrm{Na}^{+}-\mathrm{K}^{+}$-ATPase, SOD, iNOS, CRP, cGMP, cAMP/cGMP 均有一定的调节作 用，其中 A 方还对 FGB，Fins, IAI, IDE, GC, Leptin, FFA, cAMP 有调节作用, B 方还对饮食量、Fins、IDE 有调节作用, $\mathrm{C}$ 方还对饮食量、 $\mathrm{FGB}$ 有调节作用. 从 三方作用的效应谱来看, $\mathrm{A}$ 方对大鼠成模后第一阶段 的干预效果优于 $\mathrm{B}$ 方和 $\mathrm{C}$ 方.

从图 6B 中可以看出, 中药 $\mathrm{A}, \mathrm{B}, \mathrm{C}$ 三方对大鼠成 模后第二阶段的 Weight, BP, Fins, IRI, $\mathrm{Na}^{+}-\mathrm{K}^{+}$ATPase, SOD, iNOS, CRP 均有一定的调节作用; 其 中 B 方和 C 方还对 IDE, SS, Leptin, TG, TC, LDL-C, FFA, cGMP 有改善作用, B 方还对饮食量、FGB、 HDL-C、Apo-A、RPB4、Hcy、cAMP、cAMP/cGMP 有改善作用. 从三方的综合效应来看, B 方对大鼠成 模后第二阶段的干预效果优于 $\mathrm{A}$ 方和 $\mathrm{C}$ 方.

从图 6C 中可以看出, 中药 $\mathrm{A}, \mathrm{B}, \mathrm{C}$ 三方对大鼠成 模后第三阶段的饮食、饮水量、抓握力、 $\mathrm{BP} 、 \mathrm{FGB}$ 、 IRI、 $\mathrm{Na}^{+}-\mathrm{K}^{+}$-ATPase、SOD、iNOS 均有一定的调节 
作用; 其中 B 方和 C 方还对大便和小便量、Fins、IAI、 TG、TC、FIB、cGMP、cAMP/cGMP 有改善作用; C 方还对 IDE, GC, SS, Leptin, Hcy, LDL-C, HDL-C, FFA, Apo-A, TXB2, 6-Keto-PGF1, cAMP 等有改善作 用. 从三方的综合效应来看, $\mathrm{C}$ 方对大鼠成模后第三 阶段的干预效果优于 A 方和 B 方.

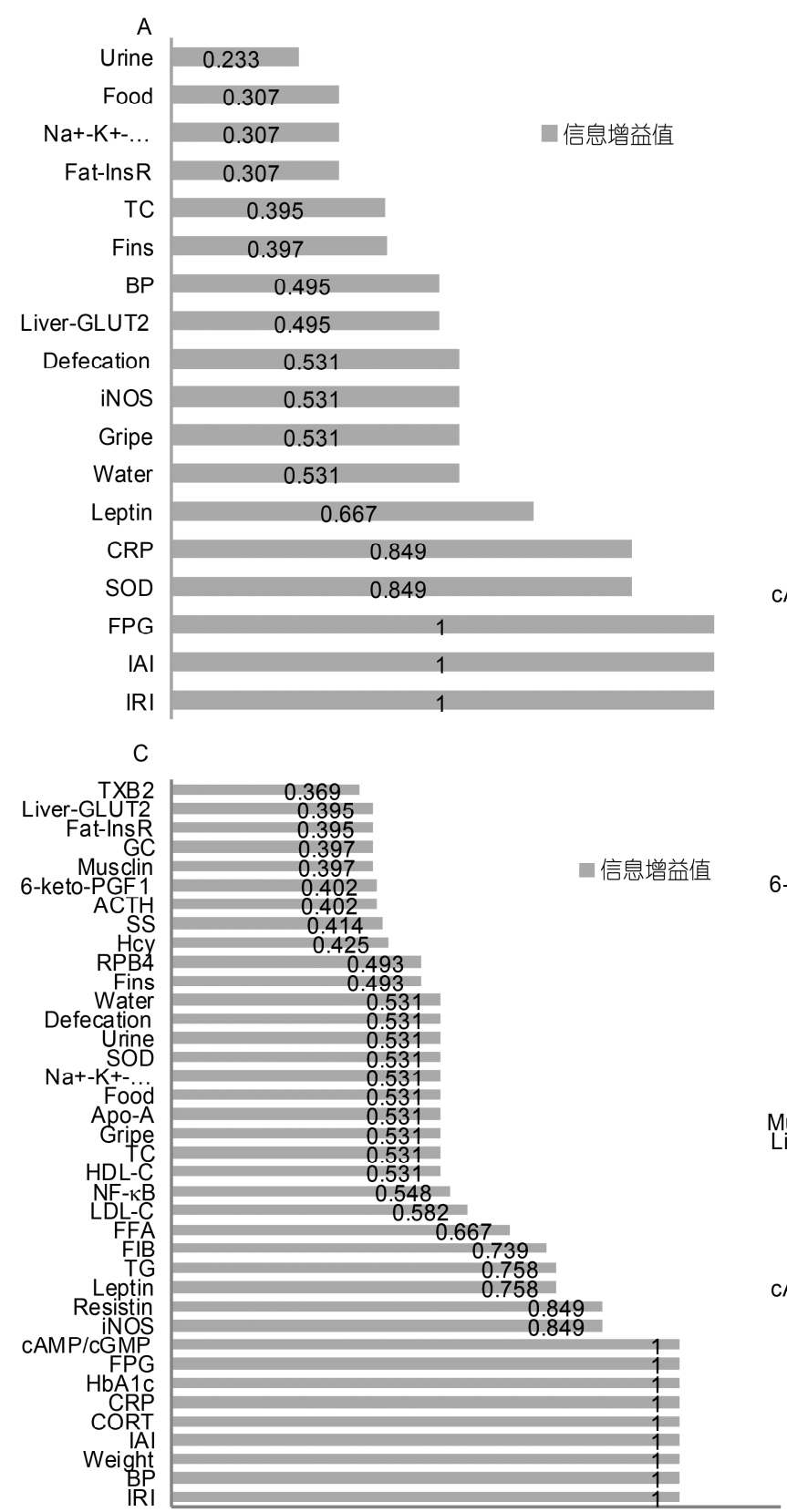

\section{3 讨论}

\section{1 基于中西医有关认识对该模型病证特点进行} 解析

本研究显示, 采用高脂饲料喂养+STZ 小剂量腹 腔注射的方法复制出的动物模型具有高血糖、高胰

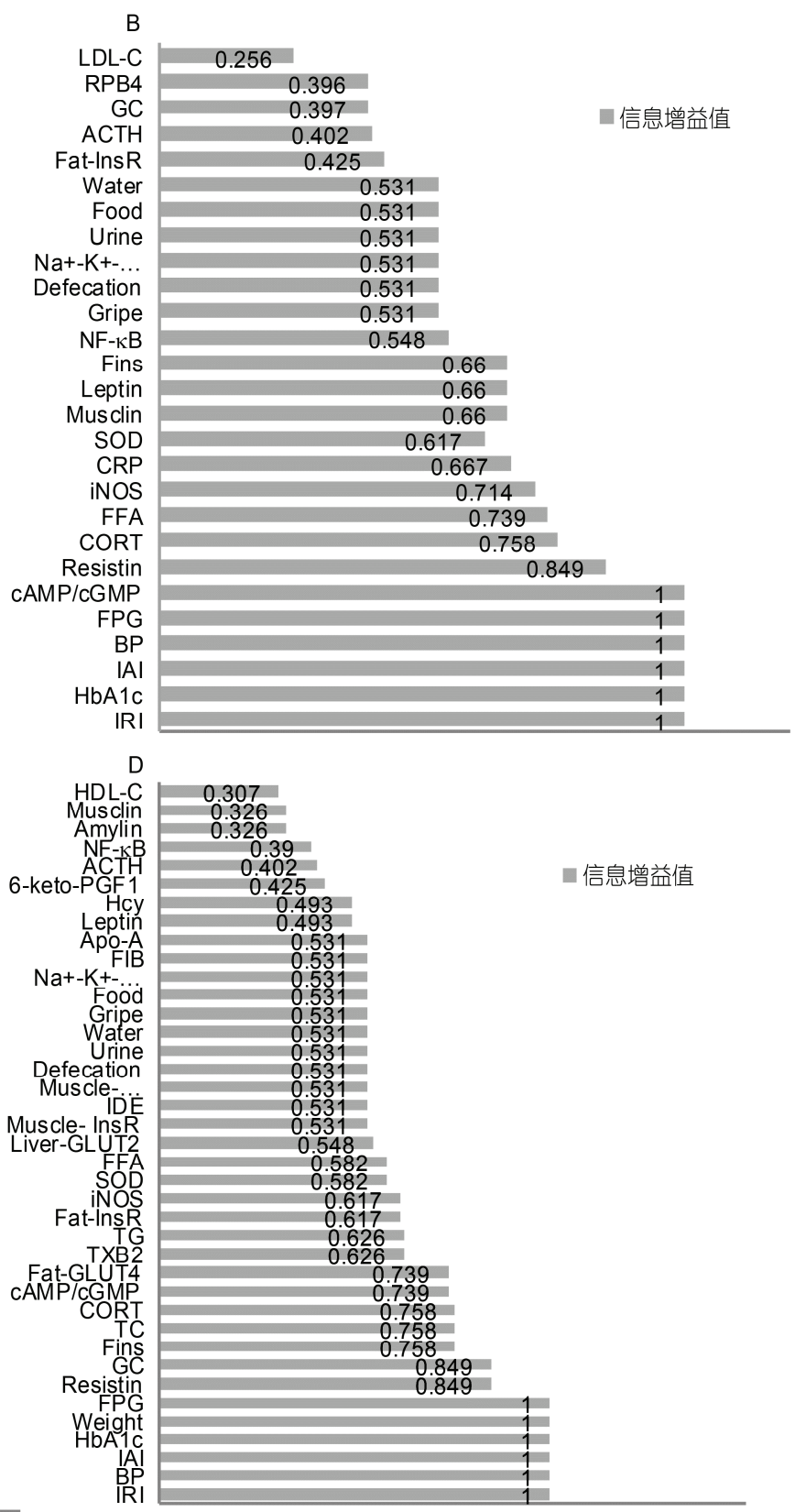

图 4 不同阶段模型与正常组指标的信息增益值比较

A: 5 周+3 天; B: 8 周; C: 10 周; D: 12 周 
岛素、高胰高血糖素、高血压、高血脂等糖尿病常见 并发症，发展过程中先后出现肝脏-脂肪-肌肉的 IR, 并伴有不同程度的炎性、神经-内分泌、氧化应激、 血液及血管等多个系统的异常变化. 同时该模型在 成模后不同阶段还先后表现出毛发光泽减退, 倦急 懒动、尾色偏红 $\rightarrow$ 被毛油绒、精神萎靡、尾巴出汗等 $\rightarrow$ 被毛减少, 臀毛枯黄, 尾部和舌质出现不同程度紫 暗及瘀斑等表现. 对其成模 (5 周+3 天)及其发展不同 时段实验室异常变化指标的分析显示, 成模后第一 阶段(6 8 周), 其全血 $\mathrm{Na}^{+}-\mathrm{K}^{+}$-ATPase、SOD、血浆 cAMP、cAMP/cGMP 显著降低, 血清 iNOS, CRP, Leptin, CORT, ACTH 显著升高; 第二阶段(8 10 周), 血清 TC, TG, LDL-C, RPB4, FIB 显著升高, HDL-C, Aop-A 显著降低; 第三阶段(10 12 周), 血浆 Hcy, TXB2, Renin显著升高, 6-keto-PGF1 $\alpha$ 显著降低. 之前

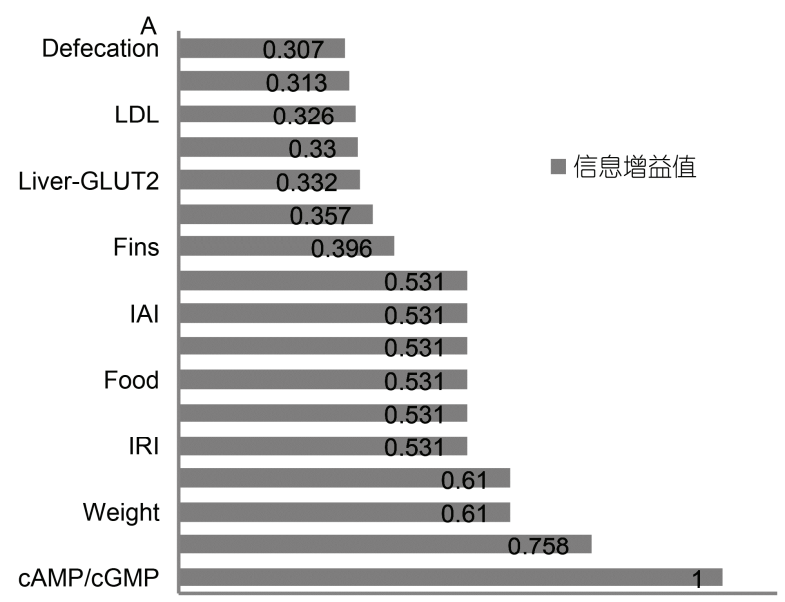

有临床研究显示, 中医气阴两虚患者多伴有 FPG 和 血中 $\mathrm{HbA} 1 \mathrm{c}$ 升高 ${ }^{[22]}$, 其血浆 cAMP 和 $\mathrm{cAMP} / \mathrm{cGMP}$ 比值显著降低 ${ }^{[37]}$; 痰浊证患者的 $\mathrm{TC}, \mathrm{TG}$ 及 FIB 较非 痰浊证明显升高, IAI 显著下降 ${ }^{[38]}$; 血瘀证患者的血 ET 和 TXB2/6-keto-PGF1 $\alpha$ 水平较非血瘀证明显增高/ 降低 ${ }^{[39]}$. 由此推测, 该模型在其发展中具有中医“气 阴两虚”、“气阴二虚兼痰浊”、“气阴二虚兼痰浊瘀血” 的证候先后演变的特点.

\section{2 基于 3 种数据分析法对 T2DM 中医相关证候 内涵进行表征}

数据聚类分析显示, 正常组和模型组以及模型 发展 4 个时间点的指标体系之间能够进行有效区分; 信息熵分析显示, 正常组和模型组以及模型发展 4 个 时间点均可以用不同的指标群进行区分. 对差异直

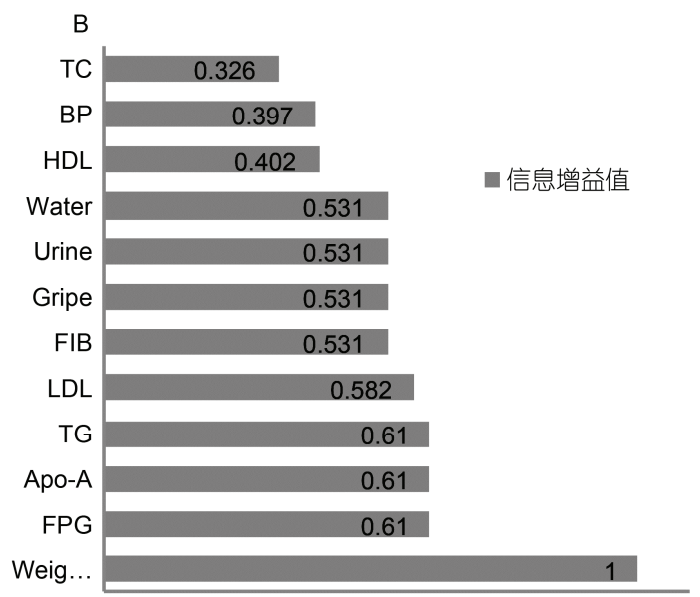

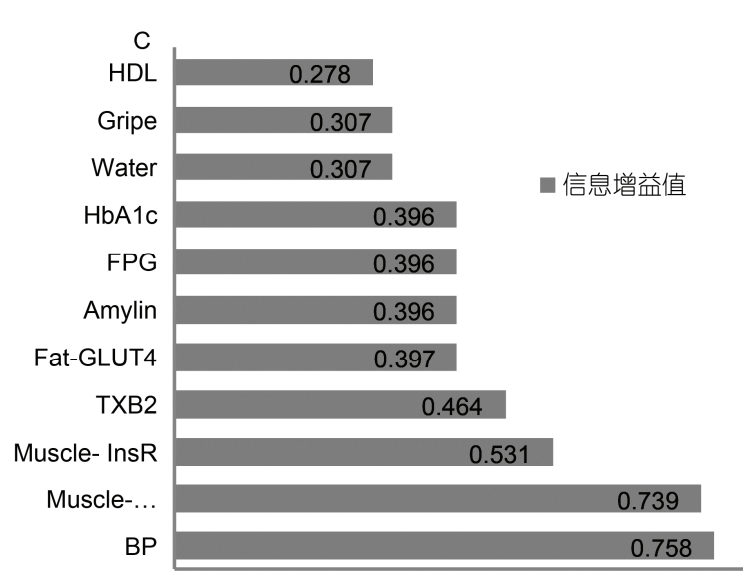

图 5 模型组不同阶段各指标信息增益值的比较

A: 模型组 5 周 +3 天与 8 周各指标信息增益值的比较; B: 模型组 8 与 10 周各指标信息增益值的比较; C: 模型组 10 与 12 周各指标信息增益 值的比较 


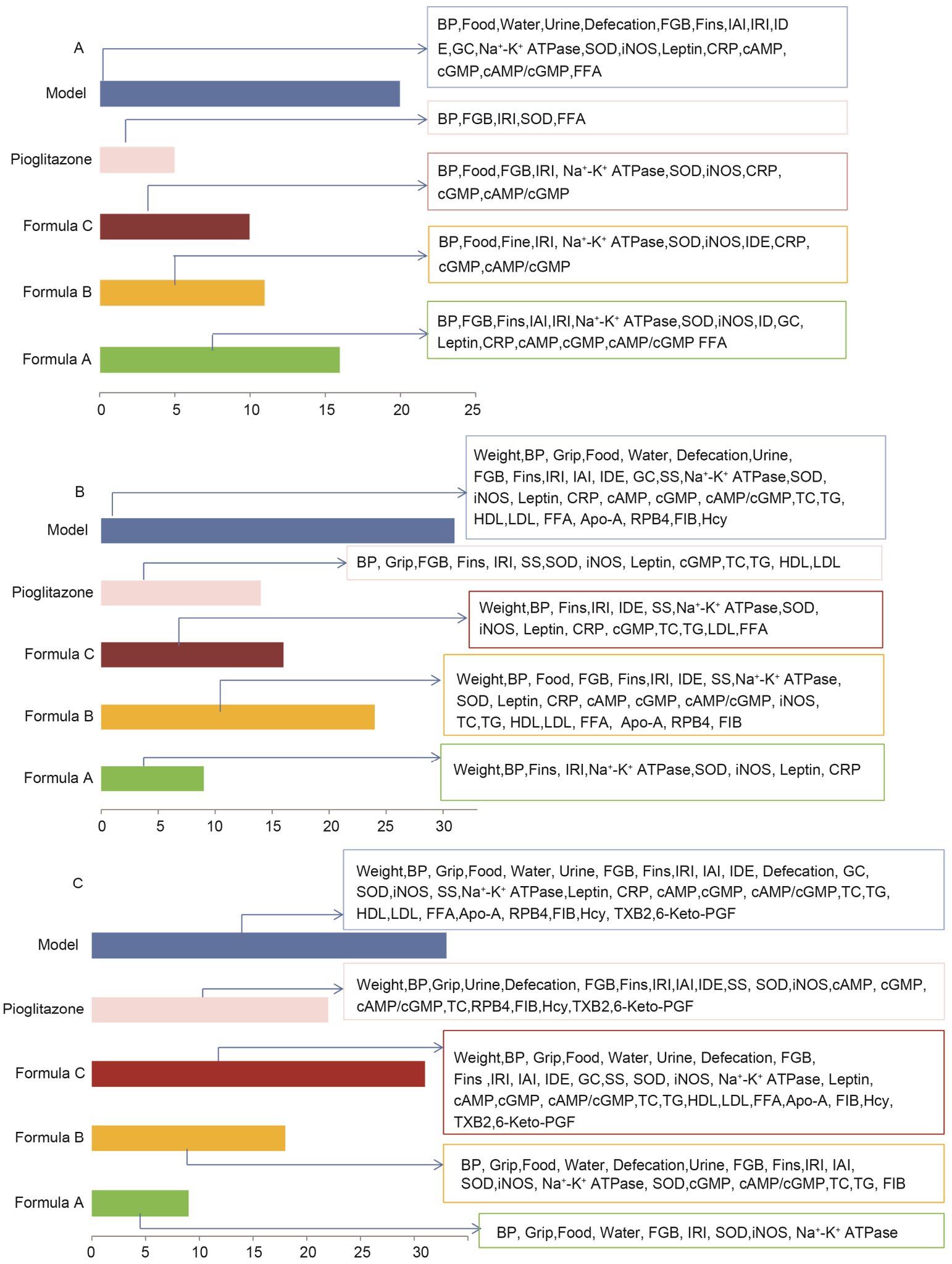

图 6 大鼠成模后不同阶段指标变化及相关方药的干预作用

$\mathrm{A}$ : 第一阶段; B: 第二阶段; C: 第三阶段 
观分析、聚类分析和信息熵分析方法各自所获得有关 模型阶段特征性指标进行综合见表 4. 从表 4 中可以 看出, 直观分析与信息熵分析所获指标中有不少相 同的内容, 但直观分析法所获得的指标较信息熵法 多, 可能与两种方法基于的数据库以及增益值取值 标准不同有关.

根据表 4 整合其中的共同指标，获得该模型发展 3 个阶段的病变指标群见图 7. 从图 7 中可以发现成 模时指标群(CRP, Leptin, Defecation)主要涉及炎症反 应; 成模后第一阶段(早期)指标群(FPG, IAI, IRI, HbA1c, Resistin, FFA, cAMP/cGMP, CORT, iNOS, $\mathrm{Na}^{+}-\mathrm{K}^{+}$-ATPase, SOD, BP, Food, Water, Urine)主要涉 及胰岛素抵抗、脂肪分解增加、神经-内分泌功能紊 乱、氧化应激反应等，出现高血压和中医“三多症”; 成模后第二阶段(中期)指标群(TG, TC, LDL-C, HDL-C, Apo-A, FIB, Weight)主要涉及脂代谢紊乱、 凝血功能异常等, 并出现“消瘦症”; 成模后第三阶段 (后期)指标群(TXB2, 6-keto-PGF1 $\alpha$, Amylin, Muscle-InsR, Muscle-GLUT4)主要涉及血管调节异 常、胰岛损伤、肌肉胰岛素抵抗. 提示这些指标群与 中医不同阶段的证候有一定的关联, 相关指标群的 病理学含义可为中医阶段性证候即“气阴两虚证”、 “气阴二虚兼痰浊证”、“气阴二虚兼痰浊瘀血证”的现 代内涵提供理解.

\section{3 结合方一证效应对中医证候内涵表征的进一 步评价}

基于“方证关联”, ${ }^{[40]}$ 的原理，本研究中设计的 A, $\mathrm{B}, \mathrm{C}$ 三方分别为 2 型糖尿病模型大鼠发展第一阶段 气阴二虚证、第二阶段气阴两虚兼痰浊证、第三阶段
气阴两虚兼痰瘀证的针对性治方 (目标方). 为加强研 究的论证性, 各点除目标方外, 同时还设置了其他二 首关联治方(对比方)进行同比观察, 试图通过三方对 各阶段不同证候干预效应的系统评价, 即通过方证 关联性大小来验证上述三证内涵表征的合理性. 结 果显示, 三方对模型不同阶段的异常变化指标均有 不同程度的改善作用，但各方干预效应有所不同. 三 方所对应各阶段的效应谱中的关联指标群见图 7 .

从图 7 可以发现, A, B, C 三方分别对大鼠成模后 第一、第二、第三阶段异常指标群具有更好的改善作 用，表明中医据证立法的治方对模型演变不同阶段 干预效果显示出因证选择性. 进一步对三方各阶段 的效应谱与模型各阶段特征性指标谱进行比较, 可 以发现 $\mathrm{A}$ 方能显著改善成模后第一阶段指标群(BP, Food, Water, Urine, FPG, IAI、IRI, HbA1c, FFA, SOD, iNOS, $\mathrm{Na}^{+}-\mathrm{K}^{+}$-ATPase, cAMP/cGMP, CORT, Resistin) 中的 BP, FPG, IRI, IAI, FFA, $\mathrm{Na}^{+}-\mathrm{K}^{+}$-ATPase, SOD, iNOS, cAMP/cGMP(其中 CORT, Resistin, HbA1c 未纳 入本次干预的观察范围); $\mathrm{B}$ 方可显著改善成模后第 二阶段指标群(Weight, TG, TC, FIB, HDL-C, LDL-C, Apo-A)中的全部指标; C 方可显著改善成模后第三阶 段指标群(TXB2, 6-keto-PGF1 $\alpha$, Amylin, MuscleInsR, Muscle-GLUT4)中的 TXB2 和 6-keto-PGF1 $\alpha$ (其 中 Amylin, Muscle-InsR, Muscle-GLUT4 未纳入本次 干预的观察范围). 结果显示, A, B, C 三方对模型第 一、第二、第三阶段的中医证候表征性指标群的确有 较高的选择性改善作用. 该结果为基于数据分析所 获得的模型中医证候表征的合理性提供了一定的实 验治疗学旁证.

\section{表 4 基于不同分析方法获得的模型各阶段特征性指标}

\begin{tabular}{|c|c|c|c|c|}
\hline & 5 周+3 天 8 周(成模第 1 阶段) & $8 \sim 10$ 周(成模第 2 阶段) & 10 12 周(成模第 3 阶段) & 5 周+3 天 12 周(成模后全程) \\
\hline $\begin{array}{l}\text { 直 } \\
\text { 观 } \\
\text { 法 }\end{array}$ & $\begin{array}{c}\text { BP, Food, Water, Urine, FPG, } \\
\text { IAI, IRI, HbA1c, FFA, SOD, } \\
\text { iNOS, CORT, cAMP/cGMP, } \\
\text { Resistin, Na }{ }^{+}-K^{+} \text {-ATPase, } \\
\text { Stool, Fins, Leptin, CRP, } \\
\text { NF-кB, GC, IDE, SS, Musclin, } \\
\text { ACTH, Liver-GLUT2, } \\
\text { Liver-InsR }\end{array}$ & $\begin{array}{c}\text { Weight, FIB, TG, TC, Apo-A, } \\
\text { LDL-C, HDL-C, Hcy, BP, } \\
\text { Grip, RPB4, Fat-InsR, } \\
\text { Fat-GLUT4 }\end{array}$ & $\begin{array}{l}\text { TXB2, Muscle-GLUT4, } \\
\text { Muscle-InsR, } \\
\text { 6-keto-PGF1 } \alpha, \text { Amylin, } \\
\text { Renin }\end{array}$ & $\begin{array}{c}\text { BP, Food, Water, Urine, FPG, } \\
\text { IAI,IRI, HbA1c, FFA, SOD, } \\
\text { iNOS, CORT, cAMP/cGMP, } \\
\text { Resistin, } \mathrm{Na}^{+}-\mathrm{K}^{+} \text {-ATP }\end{array}$ \\
\hline $\begin{array}{l}\text { 信 } \\
\text { 息 } \\
\text { 熵 }\end{array}$ & $\begin{array}{c}\text { BP, Food, Water, Urine, FPG, } \\
\text { IAI, IRI, HbA1c, FFA, SOD, } \\
\text { iNOS, CORT, } \\
\text { cAMP/cGMP, Resistin, } \\
\mathrm{Na}^{+}-\mathrm{K}^{+} \text {-ATPase, Gripe }\end{array}$ & Weight, FIB, TG, TC, Apo-A & $\begin{array}{l}\text { TXB2, Muscle-GLUT4, } \\
\text { Muscle-InsR, GC, IDE, } \\
\text { Liver-GLUT-2, Fat-InsR, } \\
\text { Fat-GLUT4 }\end{array}$ & $\begin{array}{c}\text { BP, Food, Water, Urine, FPG, } \\
\text { IAI, IRI,HbA1c, FFA, SOD, } \\
\text { iNOS, CORT, cAMP/cGMP, } \\
\text { Resistin } \mathrm{Na}^{+}-\mathrm{K}^{+}-\mathrm{ATP}\end{array}$ \\
\hline
\end{tabular}




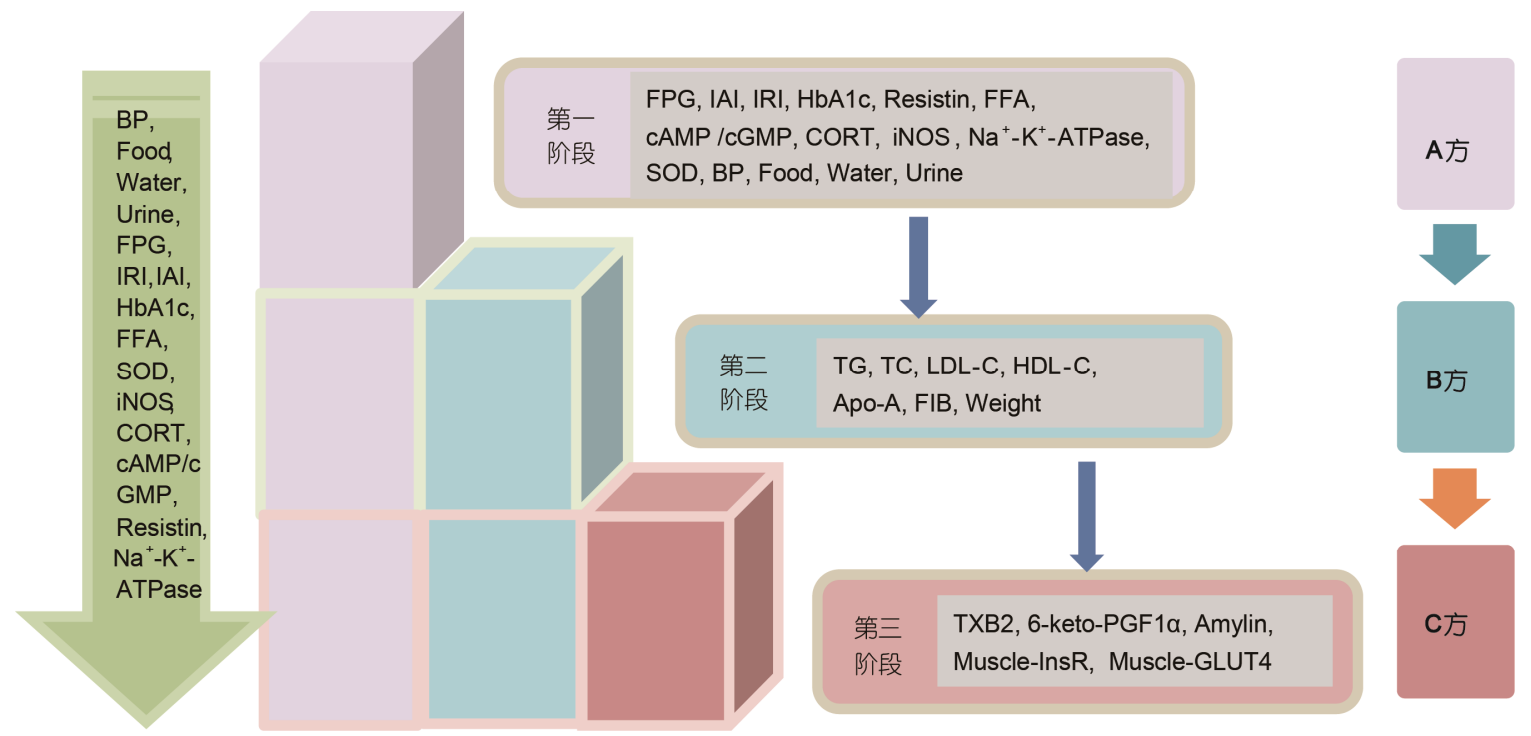

图 $7 \mathrm{~A}, \mathrm{~B}, \mathrm{C}$ 三方作用于 T2DM 模型大鼠发展 3 个阶段的关联指标群

\section{4 小结}

本研究基于病证结合的理念, 以 $\mathrm{T} 2 \mathrm{DM}$ 的现代 病理认识和中医防治经验为背景, 对高脂饲料喂养+ 小剂量 STZ 腹腔注射诱导的 T2DM 大鼠模型病证演 变的特征进行较为深入的研究. 实验中通过跨系统 多组数据观测和运用多种方法对数据结果进行系统 分析, 获得该模型大鼠的基本病理特征和其因时变 化的病生理学内涵, 为现代认识 T2DM 发生发展的 病理机制提供了重要参考. 同时基于中医证候的认 识, 结合实验室指标的变化, 在发现该模型发展不同 阶段具有中医证候演变特点的基础上, 通过对数据 分析结果的整合, 初步提出该模型各阶段中医证候 现代内涵的表征, 并进一步依据方证关联的原理, 设 计体现关联治法的 3 个不同方剂, 系统比较观察三方 对该模型不同阶段证候的干预效应. 结果显示, 因证 治方的干预效用分别与不同阶段的证候表征指标群 具有更好的关联, 为模型研究所获得的有关 T2DM
中医病机(气阴两虚、痰浊、瘀血)发展演变中的证候 现代内涵表征提供了支持.

基于中西医病证的现代内涵，本研究首次采用 动态跨系统多组指标探查和综合多种数据分析方法, 探讨并获得 T2DM 模型演变中各阶段西医的病生理 学特征和中医证候的现代内涵表征. 需要指出的是, 由于遗传与环境复杂的相互作用关系, T2DM 临床发 病具有人群的多态性, 发病机制也不完全相同, 其中 医的临床证候演变也可能具有多种模式. 本次基于 T2DM 病证结合动物模型发病机制探查所获得的结 果可能揭示了 2 型糖尿病中的部分发病类型及其中 医证候特点, 且有待于临床的进一步验证.

该项探索对于揭示基于疾病为背景的中医证候 生物学内涵提供了一定的方法学途径, 为从证候演 变的角度论证中医辨证论治经验及“方证相关”的合 理性提供了一定的科学依据, 对于建立具有中医辨 证论治特色的病证结合实验治疗学平台具有参考 意义.

\section{参考文献}

1 任建勋, 刘建勋, 林成仁, 等. 冠心病不稳定性心绞痛患者气滞血瘀证和气虚血瘀证的生物学基础比较分析. 中国中西医结合杂 志, 2010, 30: 352-356

2 孙静云, 顾赛红, 周仲瑛, 等. 证的研究中几个重要问题的反思与展望. 中医杂志, 2014, 55: 1171-1175

3 赵燕, 王天芳, 于春光, 等. 关于中医临床研究中症状信息采集的思考. 中医杂志, 2005, 46: 883-884

4 Korkmazer E, Solak N. Correlation between inflammatory markers and insulin resistance in pregnancy. J Obstet Gynaecol, 2015, 35: 
$142-145$

5 雷燕, 王振华, 刘剑刚. 血脂异常中医证候规律及其客观化研究. 中国中西医结合杂志, 2007, 27: 1074-1077

6 陈建新, 赵慧辉, 王伟. 中医证候生物学基础研究思路初探——基于特征选择的数据挖掘方法. 中西医结合学报, 2010, 8: $747-749$

7 黄粤, 高颖. 数据挖掘技术在中医证候研究中的应用概述. 上海中医药大学学报, 2010, 24: 85-87

8 李梢. 中医证候生物分子网络标志的构想与研究. 中医杂志, 2009, 50: 773-776

9 白云静, 申洪波, 孟庆刚, 等. 基于共轭梯度下降算法的类风湿关节炎 BP 神经网络证候模型研究. 中国中医药信息杂志, 2010, 17: 96-97

10 李晓红, 梁媛, 李晶晶, 等. 系统生物学与中医证本质研究. 中国中医基础医学杂志, 2011, 17: 211-212

11 赵琰, 韦姗姗, 续洁琨, 等. 从异病同证角度探讨证候的生物学基础. 中医杂志, 2014, 55: 429-431

12 Mcgarry J D. Dysregulation of fatty acid metabolism in the etiology of type 2 diabetes. Diabetes, 2002, 51: 7-18

13 Wieser V, Moschen A R, Tilg H. Inflammation, cytokines and insulin resistance: a clinical perspective. Arch Immunol TherExp (Warsz), 2013, 61: 119-125

14 田萌. 2 型糖尿病患者空腹胰高糖素水平和胰高血糖素/胰岛素比值随病程的演变. 山东大学学报(医学版), 2014, 52: 33-37

15 洪雨. 2 型糖尿病病程与中医证候的相关性研究. 硕士学位论文. 北京: 北京中医药大学, 2013

16 马广莣, 金秀平. 不同病程 2 型糖尿病患者血清 C 反应蛋白水平的比较. 中国全科医生, 2011, 14: 494-496

17 谷浩荣, 贾春华. 糖尿病中医病机及治法研究进展. 上海中医药杂志, 2011, 45: 83-84

18 周迪夷. 2 型糖尿病中医分期辨证研究. 硕士学位论文. 北京: 北京中医药大学, 2010

19 石顷. 2 型糖尿病血糖波动与中医证型的相关性研究. 硕士学位论文. 北京: 北京中医药大学, 2012

20 淦家荣, 杨柏枫, 刘红英, 等. 120 例 2 型糖尿病中医辨证分型与胰岛素抵抗及有关因素的分析研究. 湖南中医杂志, 2007, 23: 9-11

21 郑姜钦, 马坤, 吕绍光. 2 型糖尿病中医辨证与胰岛素抵抗的关系. 中华中医药学刊, 2010, 25: 1318-1320

22 龚燕冰, 倪青, 高思华, 等. 2 型糖尿病主要理化指标与中医证候相关性的贝叶斯网络分析. 中华中医药杂志(原中国医药学报), 2010, 25: 31-33

23 郭仁真. 糖尿病中医证候演变规律研究. 硕士学位论文. 北京: 中国中医研究院, 2005

24 申涛，黄晓华，欧亚龙，等. 2 型糖尿病患者中医辨证分型与胰岛素抵抗的关系. 中国中医药科技, 2011, 18: 235

25 李芳生. 中医阴阳学说的分子基础. 辽宁中医杂志, 1998, 25: 156-157

26 赵玲, 魏海峰, 张丽, 等. 中医痰浊血瘀证候的生物学基础研究. 中华中医药杂志, 2008, 23: 680-683

27 徐远. 中医治疗代谢综合征的思路与方法. 中医杂志, 2003, 44: 301-302

28 唐迎香. 2 型糖尿病胰岛素抵抗与中医痰瘀毒相关性研究. 中国医药学报, 2004, 19: 237-239

29 李敬林, 王铁椐 郑殿军, 等.气阴两虚非胰岛素依赖型糖尿病的临床实验指标观察. 中国中西医结合杂志, 1994, 4: 166-168

30 韩丽蓓, 杨惠民, 崔红霞, 等. 2 型糖尿病血脂异常的中医证候研究. 北京中医药大学学报, 2010, 33: 358-360

31 薛珺, 何秋芬, 夏婉贤, 等. 糖尿病下肢血管病变中医证型与彩色多普勒超声结果的相关性研究. 中医药导报, 2014, 20: 67-69

32 阴建国. cAMP 和 cGMP 的拮抗代谢调节与中医“阴阳”关系. 陕西中医学院学报, 1987, 1: 51-54

33 徐成兴, 叶伟成, 胡蕴刚. 120 例 2 型糖尿病患者的中医辨证分型及相关分析. 上海中医药杂志, 2007, 41: 34-36

34 陈利国, 马民，屈援,等. 糖尿病血瘀证研究进展. 中华中医药杂志, 2005, 20: 114-116

35 钱俊文, 柴可夫. 胰岛素抵抗模型形成过程的中医证候动态演变研究. 中华中医药杂志, 2006, 21: 430-431

36 刘玥, 谢鸣, 张业. 2 型糖尿病胰岛素抵抗大鼠模型相关指标的动态变化与中医证候的相关性研究. 中西医结合学报, 2012, 10: 100-108

37 张鹏, 洪宝源. 人体内 cAMP 与 cGMP 动态平衡机理的探讨. 生物化学与生物物理进展, 1985, 3: 46-48

38 孙刚, 李晓玲. 痰浊证型患者糖、脂代谢指标检测及其临床意义. 贵阳中医学院学报, 1997, 19: 59-60

39 魏爱生, 孙丰雷, 王甫能, 等. 2 型糖尿病血瘀证与血管内皮素、血栓素 B2 和 6-酮-前列腺素的关系. 中西医结合心脑血管病杂志, 2006, 4: 682-683

40 谢鸣. “方证相关”逻辑命题及意义. 北京中医药大学学报, 2003, 26: 11-12 


\title{
Characterization of TCM syndrome using model of disease combined with syndrome based on principle of system biology
}

\author{
LIU JinNa ${ }^{1}$, XIE Ming ${ }^{1}$, ZHAO Jing ${ }^{1}$, Yang Hongye ${ }^{2}$, Shen Junhui ${ }^{3}$, Wang Bangzhong ${ }^{1}$, \\ Liu Biyuan $^{1} \&$ Zhang Yuanfeng ${ }^{1}$ \\ 1 Formulary, National Key Science, Beijing University of TCM, Beijing 100029, China; \\ 2 Institute of Basic Medical Sciences, Chinese Academy of Medical Sciences, Beijing 100005, China; \\ 3 Information Center, Beijing University of TCM, Beijing 100029, China
}

Syndrome, as an important basis for clinical diagnosis and treatment of traditional Chinese Medicine (TCM), is the core element of the experience and fulcrum of theory in TCM syndrome differentiation and treatment. It is important for understanding the scientific nature of TCM to reveal the modern connotation of TCM syndrome but a difficult point in the current research of TCM. The study is to explore modern representation of TCM syndromes using principles of modern systems biology based on the characteristic of TCM syndrome evolution with time in the development of the disease and the knowledge of the pathogenesis of type 2 diabetes mellitus (T2DM). The animal model of T2DM with TCM syndrome evolution was set up, the change of multidimensional index cross systems of the model in time was investigated, and comparison of intervention effects of related formulas from TCM clinical experience was made on the different stages of the model. The system analysis of multi batch of the experiments was made using mathematical analysis methods. The results showed that the T2DM rat model, induced by high glucose and high fat fed combined with STZ injection, had the characteristics of TCM syndromes, as both deficiency of Qi-Yin, phlegm and blood stasis, orderly evolution at different stages of development accompanied by combined multi index groups of cross system involving many pathological links, such as the metabolism of glucose and lipid, nerve endocrine, oxidative stress, inflammatory response, and vascular activity. The related formulas have different intervention effects for different stages of the model. The formula designed aiming at given syndrome showed a better effective advantage among them and a certain correlation with the index groups of the corresponding stage of the disease. It may provide certain experimental evidence for demonstrating the theory of "correlation between formula and syndrome" based on experience of syndrome differentiation and treatment in TCM. It is also significant for establishing the experimental therapeutic platform with characteristics of TCM syndrome differentiation and treatment.

model of disease combined with syndrome, T2DM, TCM syndrome, intervention of TCM, correlation between formula and syndrome

doi: 10.1360/N052016-00026 